DOI: https://doi.org/10.24113/ijellh.v8i5.10599

\title{
Reader's Consciousness in Literary Interpretation with Special Reference to Stanley Fish's Reader Response Theory
}

\section{Chhabi Seth}

Student, M.Phil.

Department of English Studies

Dayalbagh Educational Institute (Deemed University)

Agra, Uttar Pradesh, India

chhabiseth28@gmail.com

\begin{abstract}
Reader Response Theory is a broad, exciting, evolving domain of literary studies that can help us learn about our own reading processes and how they relate to specific elements in the text we read. The readers do not passively consume the meaning presented to them by the objective literary text. Stanley Fish's Reader Response Theory originated with an interesting experiment that was conducted by him for proving that, 'Interpretation is not the art of construing but the art of constructing. Interpreters do not decode poems; they make them.' It is the consciousness of the reader that makes the text relevant and significant. The text has no meaning and relevance before the reader reads it and presents his own judgement and experience regarding the text. The readers are termed as the 'interpretive communities' as they analyze the text and play an active role in a reading experience.

The paper will focus on highlighting the reader's consciousness, his perception and experience which gives meaning and significance to a literary text. It will point out that the meaning does not lie in the text, but it is the consciousness of the reader which creates it and adds meaning to the text.
\end{abstract}


Keywords- Reader, Domain, Community, Interpretation, Consciousness, Relevance, Perception, Meaning

Reader Response Theory gained prominence as a unique and different theory as it attached particular importance to the reader as compared to the text. Reader-Response theory is a literary theory that focuses on the reader and their experience of a literary work. The theory originated in 1960s and 70s in America by the literary critics such as Norman Holland, I.A Richards, Stanley Fish etc.

The theory gained prominence because of its different ideology and perspective as the traditional theories focused either on the author or on the content. The text-based approaches such as New Criticism focus on the meaning that is already present in a work by the writer but Reader-Response Criticism, being completely different from these approaches, argue that a text has no meaning before a reader reads and presents his own experiences regarding the text.

To describe reading as the process of the reader's interaction with texts is common practice in the literary theory, especially in the Reader-Response Criticism in accordance with the psychology of reading. By including both the reader and the text or the literary text if that be the case, such conceptualisation of reading makes it possible to focus on different aspects of the interaction, the reader's part in producing meaning in the process of reading conceived as either textual world or the representation of the text, the process of reading itself. The vision and the clarity of the reader, at the same time is a condition that persists through changes in context and thus a single text may have varied interpretations. The self of the competent reader never interferes with the perception of clarity and even if it does, it is always controlled by the objectivity present in his mind.

The works of Fish mark a complete shift in his earlier concept of text as a catalyst and reader as an agent. He establishes a major notion that reader not only discovers the meaning 
but he actually fills the text with meaning. He projected his reader as a member of a large group where compatibility and interpersonal relationships are valued. His notion of interpretive communities embraces the principle of change and dynamism in the reading and understanding of a particular text by different readers. He demonstrates that the interpretation of the reader reveals the real and complete vision of the writer which otherwise remains latent.

Fish holds a strong belief that the interpretation of the reader never allows the poem to die and the poetic qualities come into focus due to the reader's active participation. One of the reviewers Paul Strohm in his review titled Is There a Text in This Class?, suspected the validity and relevance of Fish's notion of 'interpretive communities' as he believed that the formation of such communities gave the readers the right to fabricate their own private meaning of a work and practise it as some rights of a citizen. Fish's work in this field examines how the interpretation of a text is dependent upon each reader's own subjective experience in one or more communities. Fish's interpretive community creates its own reality and invests a text with meaning. For Fish "everything a reader does, even if he later undoes it, is a part of meaning experience."(Fish, 8) His "interpretive community" is a wonderful fusion of individual freedom and cultural influence.

Each communal strategy in effect creates all the seemingly objective features of the text as well as the intentions, the speaker or the author that the reader may infer from the text. Therefore, the validity of any text depends on the assumptions and strategies that the readers may share with the other members of a particular interpretive community. Fish suggests that the interpretation of a literary text is characterized not by the fixed meanings according to the author and his way of dealing with the concepts, but by the practices and assumptions of the reader or the interpretive community, where the meanings are derived from the context and 
the imagination of the reader. It is the context and especially the imagination of the reader which imparts meaning to the text and so, it is impossible to separate the reader from the text.

Fish is of the view that to claim that each reader essentially participates in the making of a poem or novel is not an invitation to the unchecked subjectivity and to the endless proliferation of competing interpretations. Each and every reader approaches a literary work not as an isolated individual but as part of a community of readers. As he says, "it is the interpretive communities, rather than either the text or reader, that produce meanings."(Fish, 67)

The concept of "interpretive communities" separates Stanley Fish from the rest of the critics, because his reader is not an individual but is a part of a group containing similar people like him and together advocating the future of the text. Before dwelling deeply into this assumption, the basic qualification of being a part of this community is of an interest. This will also throw light on the relationship between literary criticism and language, structure and matter. It is the interpretive community rather than the reader or the text, which exposes meanings and is responsible for highlighting the structural patterns and formal features present in a text. The communities are obviously held by members sharing similar interpretive strategies, not simply of the external readings of the texts but virtually writing and rewriting them again. Interpretation may vary but all of them are partly objective and partly subjective. It is not entirely objective because interests, purposes and goals have an impact on the interpretations and they are not subjective because they do not proceed from one man's mind but from a group of people. The external forces work on their mind to an extent and their analysis may be altered.

Fish gives more importance to the evolutionary aspect of meaning. The reader always understands the text with no possibility of achieving an objective or author-centred 
interpretation. The interpreter will realize that the formal patterns which he is looking for in the text are themselves constituted by an interpretive act. He also claims,

Theories always work and they will always produce exactly the results they predict, results that will be immediately compelling to those for whom the theories assumptions and enabling principles are self-evident. Indeed, the trick would be to find a theory that did not work. (Fish, 10)

Fish's theory seems to bring out such readers and such communities, who not only react to a text but also, observe their own reactions. He emphasizes on the process of self-observation of well-knowledgeable people, who possess limitless knowledge. His readers stand above the common man. They are competent in language and linguistic dimensions. They have to be sound about the abstract objects and about reality also. Real readers emerge competent in whatever situations they are placed in. Their approaches are supposed to be organised and coherent, only then their interpretations will become comprehensible. The realisation of one factor is important for them that their interpretation must not expose an appropriate way of reading, but their interpretations should be such that they may arouse the possibilities of several other interpretations. Their interpretation, if aroused under all these characteristics, may be specified for evidences to others but again they would not remain permanent.

The importance of the Reader Response Theory is that it allows the readers to interpret the text in various ways to look past the words of the text and search for the deeper meanings and allows them to see the different perspectives of others while reading. It may be possible that the reader may bring their personal interpretations and biases to the text rather than examining the real meaning to it. But Stanley Fish opines that the readers in his theory are intellectual and are of knowledge and understanding not just any other person who may not be able to analyze the text in the real light because for analyzing and interpreting 
something, knowledge is required. He said that his reader is a scholar, a well-informed person and not just an ordinary one.

Fish believes that the only way of approaching a literary text for interpretation is the way of intention. Yet, the meaning of intention is different for him. The reason for his belief is that "meanings are not embedded in words but emerge and are perspicuous in the light of background conditions of intelligibility." (Fish, 40) Further Fish believes that intentions and assumptions come first and meaning second. Intentions do not constrain interpretation, they actually add new dimension to it. A text is neither ambiguous nor unambiguous in itself. It acquires a shape and significance only within the assumed background circumstances of its possible use. Fish then visualizes no difference between literary and legal interpretation, in the different kinds of texts they address. He thinks that the textual differences are themselves constituted by already differing interpretive strategies. The textual differences do not come because of the different areas of study.

Fish completely denounces the concept of compartmentalization as he strongly believes that no discipline or activity can be studied in isolation. All the branches of knowledge exist in the networks of affiliation and connectivity. The texts and their study and interpretation are positioned in a similar kind. There is structural interdependence between the texts and the reader, they are contextual.

Stanley Fish in his essay, 'How to Recognize a Poem When You See One', continues to explain his view regarding the Reader Response Theory and argues that the process of distinguishing certain features of an object follows "the act of recognition". Fish offers such conclusions from a short anecdote, which illustrates an analytical response of a group of students to five names he wrote on the board.

He conducted an experiment on his students who were confined to the study of religious poetry of the seventeenth century. He had been discussing about some literary 
critics with the earlier group so, he had written the names of some critics on the board and before the students of poetry came, he drew a box around those names and wrote 'p43' on the top of it. The names of the literary critics included-

\author{
Jacobs- Rosenbaum \\ Levin \\ Thorne \\ Hayes \\ Ohman (?) (Fish, 69)
}

The students of poetry interpreted it in different ways, taking their study of religion into consideration. All of them related the names of the literary critics to the different terms taking it to be associated to Christ and Bible. Even various analyses were given in relation to the way in which the names were written, like for example taking it to be a kind of religious cross etc. As they were the students of Christian symbols and Biblical allusions, they spontaneously analyzed it and extracted meaning to it in connection to their religious studies. According to Fish, it was because their minds were trained with religious poetry and therefore they interpreted everything like this same as in religious context. The students, who focused on the Christian symbols and Biblical allusions, spontaneously analyzed it and extracted meaning from the list of the names of the literary writers.

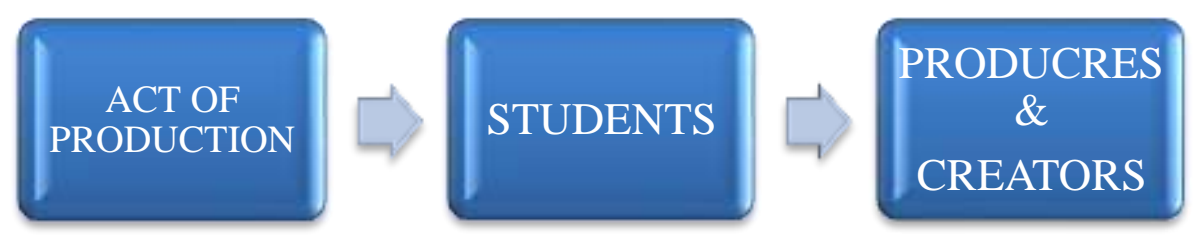


The readers perform the act of production, i.e., they produce and create different interpretation and not just configure its meaning and decode it as Fish's students did by creating completely new ideas and interpretations with the names of the literary critics. Therefore, Fish says that his students are the real interpreters as they have the knowledge of creating and producing something which is completely new.

Though many of the critics raised arguments in relation to his view that the students interpreted the names in a religious aspect which is a one-dimensional study, as their minds were completely occupied by the study of religion, they have performed. But this makes them real interpreters because they produce new interpretations as Fish says that even if they were given blank board to interpret its emptiness, they would have interpreted it in relation to God and religious touch, which is truly the act of production that has to be performed by a reader or an interpreter.

Fish gives his own analysis on the basis of the experiment conducted by him. He realized that first it was the act of recognition that came on the part of the interpretive community. The act of recognition was based on their formal training. The collection of words also held an informing purpose, where the individual words began to suggest themselves. In one of his chapters in this book, Fish postulates the fact,

Literature, I argue, is the product of a way of reading, of a community agreement about what will count as literature, which leads the members of the community to pay a certain kind of attention and thereby to create literature. Since that way of reading or paying attention is not eternally fixed, but will vary with culture and times, the nature of the literary institution and its relation to other institutions whose configurations are similarly made will be continually changing. (Fish, 72) 
Fish states that the interpreter derives this knowledge of operations from "a publically available system of intelligibility," or in other words from the sources of education such as books, teachers, and "producers" of literature. The interpreter's thoughts, in essence, are the products of the quality, quantity and focus of the source of intelligibility.

Therefore, it is the Reader Response Theory that allows for inferences and insights by the reader, just as Fish's students had done by providing new insights and so it is right to call a reader as a 'producer' and a 'creator'. According to Fish, the attention, the perspective and the approach to the text matters a lot. His students were told that the names were a poem, therefore they interpreted it as a poem and did not look for the common features that a poem possesses but rather, they started analyzing and interpreting it as a kind of poetry.

Typically, Reader Response Theory revolves around the phenomenon of 'Respond to Reading'. The theory identifies the reader as a significant and active agent who imparts the real meaning of the text by interpreting it. The theory argues that the text does not has meaning in isolation unless the reader reads and presents his own views on it. According to the Reader Response Theorists, it is only this reading experience of the readers that brings the text alive. As Fish states,

The concept of reading as the interaction between the reader and the text makes it possible to examine some less studied dimensions of the reading process and the literary experience. It centres attention on what the readers do when they actually read and on their own contribution to the mental representation of the text. (Fish, 26)

An author is an encoder as he formulates the message and a reader is a decoder as he understands the message but according to Stanley Fish, his reader is more than just being a decoder because he analyzes, interprets and re-creates the text based on his views and 
thoughts. According to Fish, it is a restricted view of a reader, if he is only considered to be limited in interpreting the text by just understanding its meaning or decoding it.

Therefore, he proves his idea by saying,

"It is not that the presence of poetic qualities compels a certain kind of attention but that the paying of a certain kind of attention results in the emergence of poetic qualities. . . Interpretation is not the art of construing but the art of constructing. Interpreters do not decode poems; they make them" (Fish, 26-27).

The interpreter's aim or purpose is not to find out the meaning or just to understand the meaning of the text but very much more than that, i.e., constructing and producing something which is new and innovative as he is producer and a creator. The role of a reader is important in constructing the meaning of a work of literature. It not only allows for, but even interests itself in how the meanings change from reader to reader and from time to time, i.e., though all the readers may interpret the same text but all of their views would vary and would be different not at all being the same.

Therefore, the experiment of Stanley Fish in his classroom proves the tenets of the Reader Response Theory that it keeps the reader at its centre, taking into consideration the importance and significance of the reader and not the text like the New Criticism. It accepts that a reader's background knowledge and experiences impacts and influences his interpretation of a text as it was the case with his students.

Reader response criticism takes into account the reader as the most important among the text and the author. The purpose of a reader's response is examining, explaining and defending his personal reaction to a text, which is called the Reader- Response Theory. Reader Response critics investigate the elements that are involved in the crucial interaction between the reader and the text. 
A reader is the creator of the text after the writer writes and publishes his work. He fears no relation with the author or his intentions in the text. He treats text as a text and so his interpretations are his own new achievement. This happens with every reader. So, every reader approaching a text has a new interpretation, different from the previous reader and an entirely new one also. One reader's interpretation thus comes to an end with his reading. He is a responsible reader, conscious of the purpose of interpretation and also of the fact that his reading experience is a self-consuming task.

A reader consumes the text first, but gradually he gets consumed himself and what remains is his own imagination and interpretation regarding the text. His interpretation may serve as a background for the next interpretation but it does not form the basic structure. It may be called the self-consuming activity of the reader as an act of charity which helps in the spurning up of several other interpretations and makes a contribution to the world of criticism or rather the Reader-Response Criticism. What remain common even in these various interpretations is the true principle and a close scrutiny of the text. The style may be similar but the subject matter always differs. Fish says that,

The results in interpretations are simultaneous fixed and arbitrary, fixed because they are specified apart from contexts and arbitrary because they are fixed and because it is in the contexts that the meaning occurs. (Fish, 67)

Fish keeps the reader in the centre, as his focus is on the change in the reader himself. The change then gives birth to two methods of viewing at the world around the reader. The reader may then either adopt a natural and a more reasonable way of understanding the world or adopt a path which is opposed to reasoning. In the first method, there is a demarcation between the world of reality and the world of ideas. The world of reality is considered as an organized set of objects. The second method establishes a union between these two worlds and the line of difference between them vanishes. This movement or transition is possible in 
the dialectical experience of the reader. Here a reader gets enough time, space and freedom to study all the avenues of the text and thus, create a new set of ideas and conventions. The world of ideas then is united with the world of reality. A dialectical experience treats a text as an open-ended entity and gives the reader liberty to have his own interpretation. Present comes only when past goes. Fish presents his hermeneutic cycle by believing that the previous statements and conclusions never change, but the reader does.

A thorough analysis of the critical work certainly reveals that a text is a catalyst and a reader is its agent. A dialectical text or a dialectical presentation is time bound as well as timeless, temporal as well as eternal. Fish's reader considers a text as a catalyst, which is stable and remains unchanged forever but it allows everything surrounding it, to change. A text remains the same, what changes is the perception of the readers, reading it. A reader is an agency, who creates to a text and is subject to constant changes. It is the text, as Fish views, which precipitate the event and the moment of interpretation.

Fish, in a simple and unbiased way lays down the basic principle of criticism. "Criticism is an act of judging and interpreting a work of art from the dimensions never done before." (Fish, 154) His theory revolutionized the world where initially, only the text or the author was significant. He probed into the psyche of the reader. Fish's observations reveal that an ideal reader must be courageous and possess a noble soul to develop an insight into reality. His reader needs to be a voracious reader. A reader should not ponder upon the number of illustrations given, as the number of new interpretations which he has given, are more important. He needs to unravel the truth and combine his own interpretations to the text. An ideal reader must be an organizer also. According to Fish, every discourse is like a living creature. It should be put together that it has its own body, with its components composed in such a way that they are in union with each other and the whole. 
As Tyson points out that, "Any time an essay analyzes the act of reading or readers' responses, one could classify that essay as Reader-Response Criticism.” ( Tyson, 185-188)

Tyson explains that the Reader-Response Theorists share two beliefs:

1. The role of the reader cannot be omitted from our understanding of literature.

2. Readers do not passively consume the meaning presented to them by an objective literary text rather they actively make the meaning they find in literature.

In his argument Stanley Fish, warns that any analyses generated by the assumption that meaning is embedded in the text itself, will always point in as many directions as there are interpreters. In each of the disputes analyzed by Fish, he points out that the responsibility for judgement and interpretation is transferred from the text to its readers. Meaning is not in the text but it is created by the reader's experience. This type of literary criticism insists that works are not universal.

According to Norman Holland, "The reader, to a large extent, recreates the text in his image." (266)

Fish's approach to the Reader-Response Criticism emphasizes the role of the reader in the process of reading. In a field of literary criticism that often focuses on the object of the text or on the context of the production of the text (it's historical, social, cultural contexts), Fish's focus on the reader adds a refreshing approach to the appreciation of the complementary nature of the literary process. The discovery of meaning completely becomes the task of the reader and not the philosopher or even the author of the text. Thereby, the old principles are opposed and also changed keeping in view the active reader who is ushered into a new world of interpretation. This experience, as Fish says is "nothing less than a conversion, not only a changing, but an exchanging of minds." (Fish, 6)

Stanley Fish through his reader-response criticism revolted against the text-centred approach of the New Critics and brought the readers into the centre from their marginal 
position. New criticism, which contained a search for an essential body of standards in literature, restricted the discussion and dialogue of a reader within an agreed framework, which thus undermined the reader's own appreciative sensibility. The American critic, Stanley Fish emerged on the critical scene, reacting to the supposed scientific agenda of the New Critics, with his view that the meaning of the poem is in its results, in the reading process. He proclaimed the advent of an era, which can be termed as "beyond New Criticism". (Fish, 6)

The works of Fish certainly enunciates,

In the deserts of the heart

Let the healing fountain start

In the prison of his days,

Teach the freeman how to praise. (Fish, 7)

For Fish, meanings do not exist as such but are produced. They are produced by a system of articulation from which, neither the author nor the reader can separate themselves, because they both are situated within it. At the same time, Fish proposes that in interpreting a text, a reader must also invoke interpretations. Readers must also develop the strategy of self consciousness, of keeping an eye on the larger conditions and other disciplines that make interpretation possible.

Fish establishes a major notion that the reader not only discovers the meaning but he actually fills the text with meaning. He projects his Reader Response Theory as also the theory of subversion. The work, Is There a Text in This Class?: the Authority of Interpretive Communities also becomes significant as it furnishes explanation to various objections raised by the earlier critics regarding the utter subjectivism in his approach. He projected his reader as a member of a large group where compatibility and interpersonal relationships are valued. His notion of interpretive communities embraces the principle of change and dynamism. He 
demonstrates that the interpretation of the reader reveals the real and complete vision of the writer which otherwise remains latent. The reader oriented criticism of Fish again advocates the same principle, where by his reader becomes a part of an interpretive community, guided by its principles and notions and then adjusts the gained knowledge to the interpretation of the given text.

The critical work, 'Is There a Text in This Class?' expands his critical arena by subverting the role of the creator and bringing into critical front the imagination of the reader attached to an interpretation of a literary text. Here emerges his powerful and well equipped reader, who animates a work of art. The reader becomes the central co-ordinate of the literary work and his role is explored on a larger plane.

Fish adopts a holistic approach to unravel the complexities of the subject-object dichotomy and the reader-text relationship. He analyses all these diversions with a unified but a global vision. He rejects the structuralist's notion which claims that meaning is to be found in some eternal superstructure or substructure of reality. All these aspects fall within the paradigm of his Reader Response Criticism, as he is not merely an anti-formalist or antistructuralist.

The primary contribution of Fish lies in assigning supreme position to the reader when various objective, mimetic and expressive theories were engulfing the literary critical world. Through him one comes to recognize the importance of the subject position in any contemporary critical practice. His subject-oriented criticism, keeps the individual, the reader, the speaker, the spectator, in the centre of all studies. According to Fish, one person cannot convince another about the correctness of a given interpretation by means of demonstrations that the interpretations confirm. The factor which functions the most is persuasion. Fish is then not only a pragmatist but a true rhetorician also. He is also a revolutionary who opened 
the channel of creativity and innovation in the literary sphere by bringing a reader with global consciousness.

Some Reader Response Critics term it as the notion of 'literary competence' highlighting the ways in which the reader's knowledge of conventions allows him or her to make sense of literary texts. Fish makes it clear that for interpreting something knowledge is needed and his reader is a scholar and a well informed intellectual and not an ordinary one. There are some interpretive techniques, which are social and conventional. The readers will abide to the social conventions and therefore, a reader is not an isolated individual but a part of the society.

He says, "Interpreting is accepted by the society and literature is the manifestation of the society." (Fish, 95)

Traditionally, the theories focused on meaning as something embedded in the words in a text. In this view the readers have to find or extract that meaning. But according to Fish, meaning does not just exist in the text. "Meaning happens, and it only happens when a reader interacts with a text and participates in making meaning." (Fish, 99)

The meaning is something that exists between the words in a text and the reader's mind. It is not totally in the text but it is a sort of creative engagement between the two, where the reader is at the centre of the text and adds meaning to the text through his imagination and interpretation.

Thus, Stanley Fish attaches the importance and imparts the crucial role to his reader as he says that it is the reader, who by adding his interpretive ideas and thoughts to the text adds meaning to it. He propounds that the reader is not just the taker and the accepter of the author's views but he is the constructor of the text. Therefore, Fish is of the view that without the readers' interpretation in the text, the real meaning does not emerge from the text, which 
makes the Reader Response Theory a completely different and unique theory from the other literary theories. 


\section{Works Cited}

Fish, Stanley. Is There a Text in This Class? Harvard University Press, 1980.

Tyson, Lois. Critical Theory Today. Routledge, 2006.

Richards, I.A. Principles of Literary Criticism. Macmillan India Ltd.,1995.

Holland, Norman. The Dynamics of Literary Response. W.W. Norton \& Company. 1975.

Satsangi Arti. 'Reader Response Theory and the Concept of Sahrdaya 'Shodhganga. 2006

https://sg.inflibnet.ac.in/handle/10603/202708 